\title{
Intuição para Bergson e Deleuze: atravessamentos por devires da pesquisa em Psicologia
}

\author{
Dolores Galindo \\ Universidade Federal de Mato Grosso - Cuiabá - MT - Brasil \\ Flávia Cristina Silveira Lemos \\ Universidade Federal do Pará - Belém - PA - Brasil \\ Caroline Christine Garcia do Nascimento \\ Universidade Federal de Mato Grosso - Cuiabá - MT - Brasil \\ Leonardo Lemos de Souza \\ Universidade Estadual Paulista Júlio de Mesquita Filho - Assis - SP - Brasil \\ Roberto Duarte Santana Nascimento \\ Universidade Estadual Paulista Júlio de Mesquita Filho - Assis - SP - Brasil
}

\section{Resumo}

Este artigo é uma revisão de literatura, buscando uma conversa entre Henri Bergson e Gilles Deleuze, para problematizar a intuição da pesquisa em Psicologia e o devir criança. Abrir essa conversa traz pistas relevantes que permitem deslocar percursos e movimentar territórios para fazer pensar além do dado, suspendendo juízos prévios. Assim, é possível inventar conceitos e efetuar uma atenção dispersa pela prática de pesquisa em Psicologia, saindo das essências, das lógicas lineares e causais. Devir criança é agenciar forças no lance de dados, ao acaso destas, em que o virtual se atualiza sem repetir e imitar formas. Devir criança possibilita sair da semelhança e do reconhecimento para ousar criar Psicologias outras. Palavras-chave: Bergson; Deleuze; Psicologia.

\section{Intuition for Bergson and Deleuze: let up for cross becomings in research in Psychology}

\begin{abstract}
This article is a literature review, seeking a conversation between Henri Bergson and Gilles Deleuze, to problematize the intuition of research in Psychology and the becoming child. Opening this conversation brings relevant clues that allow you to move paths and move territories to make think beyond the die, suspending previous judgments. Thus, it is possible to invent concepts and make a scattered attention through the practice of research in Psychology, leaving the essences, linear and causal logics. Becoming a child is to act as a force in the data cast, at random, in which the virtual actualizes itself without repeating and imitating forms. Becoming a child makes it possible to move from resemblance and recognition to daring to create other Psychologies.
\end{abstract}

Keywords: Bergson; Deleuze; Psychology.

\section{Intuición para Bergson y Deleuze: atravesamientos por diveres de la investigación en psicología}

\section{Resumen}

Este artículo es una revisión de literatura, buscando una charla entre Henri Bergson y Gilles Deleuze, para problematizar la intuición de la investigación en Psicología y el devir niñez. Abrir esa charla trae pistas relevantes que permiten desplazar trayectoria y mover territorios para hacer pensar más allá del dato, suspendiendo juicios previos. Así, es posible inventar conceptos y efectuar una atención dispersa por la práctica de investigación, en Psicología, saliendo de las esencias, de las lógicas lineares y causales. Devir niñez es agenciar fuerzas en el lance de dados, al azar de las estas, en que el virtual se actualiza sin repetir e imitar formas. Devir niñez posibilita salir de la semejanza y del reconocimiento para osar crear Psicologías otras.

Palabras clave: Bergson; Deleuze; Psicología. 


\section{Introdução}

Este artigo é de caráter teórico, busca realizar uma analítica conceitual da intuição e do tempo para Bergson tendo em vista a problematização da pesquisa e do pensar como aprendizado por multiplicidade e singularidade, na invenção. Segundo Gilles Deleuze, a criação de um conceito em Filosofia sempre se faz em função de um problema. Em ressonância com o pensamento bergsoniano, ele salienta que os "problemas verdadeiros" são aqueles colocados e resolvidos "mais em função do tempo do que do espaço" (Deleuze, 1999, p. 22).

O presente artigo visa contribuir para as atualizações do pensamento de Bergson via leituras mais tardias efetuadas por Gilles Deleuze, à pesquisa em Psicologia, com vistas ao escape da clausura que se converteu a desqualificação da intuição e da duração enquanto operadores possíveis na pesquisa nessa disciplina. Bergson identifica um esquecimento da duração pelos métodos de análise cientifica, sendo esse o problema verdadeiro no sentido do necessário que nos move. Para atende à finalidade deste texto, entrelaçamos as reflexões de Henri Bergson sobre intuição às de Gilles Deleuze sobre o devir criança, por considerarmos que elas permitem contemplar o tempo duração e a intuição como método quase completamente excluído das ciências modernas, dentre as quais, a Psicologia.

As provocações bergsonianas reverberam, convidando à atualização dos critérios de legitimidade da pesquisa em Psicologia, em geral, orientadas por critérios de explicitação e validação exclusivamente analíticos. Trata-se de modalidade de conhecimento que não passa pela análise que decompõe e classifica, tal como é comum às ciências modernas, em especial, à Física e à Psicologia da época, com destaque para o projeto de Psicofísica em que era apresentado o debate sobre Bergson e a Psicologia.

Concordamos com Kastrup (2000, p. 374), quando reconhece não ser possível encontrar em Bergson uma tematização sistemática da questão da criança, o que, todavia, "não impede que se busquem em seus textos, e em sua concepção de tempo, direções para pensar a criança de uma forma que considera positiva e não sob a égide do déficit ou da falta". Ainda de acordo com a autora, seguindo algumas pistas na obra de Bergson a respeito da criança, observa-se que a criança estaria mais próxima do virtual do que o adulto, dessa maneira com menos rigidez, o que a abre à invenção, quando comparada à figura do adulto.

Deleuze e Guattari (1992) afirmam que a filosofia propicia mais do que uma análise dada previamente como conceito. Assim, sua prática não se limita a reproduzir definições, tais como: produtos, formas e descobertas. Não caberia apenas ao filósofo burilar e purificar categorias supostamente pré-existentes, mas, tal como a criança, criar conceitos e seus termos de modo a sair da prisão dos universais. Ressaltam a importância do conceito como uma totalidade fragmentária, pois a unidade conduziria à impossibilidade de mutação e usos outros do mesmo. Dessa maneira, a virtualidade abre um campo de atualização como movimento de forças em um lance de dados, o qual desloca o pensar e permite colocar em suspense os dados prévios na pesquisa, de modo que haja abertura para a criação. Tanto Deleuze quanto Bergson advertem sobre os riscos dos problemas mal colocados.

$\mathrm{Na}$ arte de compor problemas, a partir do método da intuição proposto por Bergson, há um convite a abrir a pesquisa para experimentar sem aprisionamento à análise, herdeira das ciências modernas, que opera por símbolos e é incapaz de operar no tempo-duração próprio da intuição. Não se trata de uma desqualificação da análise, mas de uma definição do seu alcance:

Analisar consiste... em exprimir uma coisa em função do que não é ela. Toda a análise é, assim, uma tradução, um desenvolvimento em símbolos, uma representação a partir dos pontos de vista sucessivos, em que notamos outros tantos contatos entre o objeto novo, que estudamos, e outros, que cremos já conhecer... Isto posto, veremos sem dificuldade que a ciência positiva tem por função habitual analisar. Ela trabalha, pois, antes de tudo com símbolos. (Bergson, 2006, p.135).

O pensamento bergsoniano contribui para a Psicologia escapar da análise que opera no plano dos símbolos, herdada das ciências modernas, que nega a produção da diferença, para ousar o devir criança; ou seja, para ampliar suas potências conectivas de expandir-se e criar, por deslocamento, outros modos de operar e experimentar a produção do saber. Essa proposição implica em colocar a prática da pesquisa em variação e não restrita às amarras dos controles de variáveis e/ou de essencialismos que lhe impedem de devir criança e ganhar vida afirmativa por problematizações dos conceitos cuja gênese não é necessariamente conceitual pode ser também intuitiva.

Como observa Coelho (1998/1999), a intuição, para Bergson, corresponde a uma faculdade e a um modo de conhecimento metódico que, em absoluto, descarta a inteligência. O que está posto com a intuição não é uma oposição ao intelecto, dentre outras razões, por um elementar, qual seja, o das formas de expressão. Como expressar um conhecimento intuitivo senão pela linguagem ou por meio de uma imagem? A intuição requer do pesquisador uma distração, ou ainda, um esforço em não se limitar ao que pode ser inferido pelo raciocínio com base em fatos e conceitos pré-concebidos. Nas palavras de Coelho (1998/1999):

Um dos aspectos do método intuitivo se caracteriza pela utilização da inteligência contra ela própria, buscando uma apreensão mais direta possível dos fatos, seu verdadeiro significado, denunciando as conclusões que embora metafísicas se pretendem científicas, criando, assim, o campo propício para o surgimento da intuição propriamente dita, cuja representação envolverá novamente um grande esforço por parte da inteligência (Coelho, 1998/1999, pp. 163-164). 
As questões bergsonianas às ciências modernas e, por extensão, à Psicologia, concernem diretamente aos liames de cientificidade dos modos de produção de conhecimento que lhe dão suporte de modo a forçar a saída dos universais. Abordar a intuição para Bergson é percorrer contribuições extemporâneas de um autor cujo trabalho ainda é pouco abordado na Psicologia. Dessa maneira, ao longo deste manuscrito, potencializam-se alguns operadores conceituais em conversação de Bergson com Deleuze, para fazer ranger a pesquisa em Psicologia.

Kastrup (2007), como leitora de Bergson na Psicologia, demarca algumas pistas para a pesquisa em termos de atenção dispersa. Estar à espreita é uma delas, em um movimento flutuante do que ela denomina concentração desfocada, para poder operar a suspensão de juízos prévios como processo de problematização no acompanhamento dos movimentos atuais e virtuais. Destaca ainda que, nessa atenção suplementar, há uma inversão do fluxo cognitivo habitual, portanto, desdobra-se no alargamento da percepção, deslocando os interesses de quem percebe, havendo uma consequente apreensão direta do objeto.

\section{Notas sobre o devir criança a partir de Gilles Deleuze e Felix Guattari}

Por que abrimos um tópico para tratar especificamente do devir criança na pesquisa, neste artigo? Porque a criança, para Deleuze e Guattari (1997), efetua intensa conexão com o mundo, abre passagens para pensar possibilidades com maior expansão do que os adultos, os quais estão mais endurecidos aos encontros e reféns de práticas cristalizadas. As crianças experimentam o nomadismo do pensamento, da imanência do corpo e dos afetos no plano da produção de existências, pois operam nos entremeios e nas intercessões potentes. É nesse sentido que se pode falar de um devir criança que atravessa e rompe com modos enrijecidos de fazer pesquisa e de experimentar os encontros como multiplicidades.

Experimentar o devir criança é interessante na prática da pesquisa, na medida em que permite sair da imitação, da repetição e da posição de referendar. "Devir nunca é imitar, nem fazer como, nem uma sujeição a um modelo, seja ele de justiça ou de verdade" (Deleuze \& Parnet, 1996, p. 12). Em ressonância com a proposição de Deleuze a respeito do devir criança, Lins (2009), num plano de reflexão filosófico, formula a ideia de um devir-criança-do-pensamento, que traduzindo para a pesquisa, reverte-se em invenção de questões sem a necessidade de que se alce à interpretação, de experimentação ao invés da formalização.

A Psicologia tem sido historicamente convocada a seguir modelos científicos, baseados em cálculos e medidas, como estratégia de legitimação que Ihe traga uma filiação de ciência. Imitar e repetir, nesse caso, trouxe mais paralisia do que expansão. A pesquisa em Psicologia é mais ousada quando tem a coragem de experimentar conversações que deslocam os modelos de cientificidade modernos.
As contribuições de Bergson permitem sair de uma ontologia referencial e fundada na negação característica das ciências modernas e passar a uma ontologia afirmativa. Ao discorrer sobre a leitura de Deleuze sobre Bergson, materializada no livro Bersgsonismo, Pelbart (2009) esclarece que ao "lançar as bases de sua própria ontologia materialista, Deleuze insiste que, em Bergson, o movimento do ser se dá por diferenciação interna, e não por contradição, num jogo da determinação negativa".

Estremecer territórios para torcê-los e deslocá-los pode nos auxiliar a gaguejar na própria língua, como nos sugerem Deleuze e Parnet (1996), a fim de poder efetuar um devir minoritário para não imitar "a criança, o louco, a mulher, o animal, o gago ou o estrangeiro, mas devir tudo isso para inventar novas forças ou novas armas" (p. 15). Com efeito, problematizar através de encontros com as potências das intensidades imperceptíveis operada pelos devires. Fazer pesquisa atravessados pelo devir criança auxilia a passar por clandestinos que não se prendem pelas dívidas e ressentimentos advindos de pedidos de continuidade histórica linear e reprodutiva daqueles que desejam ser copiados e seguidos. Não se inventa por imitação e assimilação, nem por julgamento e reconhecimento e muito menos por adequações.

É nesse ponto que a singularização é acionada pela descontinuidade histórica da produção da diferença. Para a Psicologia, atravessada por devires criança, vale abandonar os modelos da descendência e da raiz de origem dos saberes, para pensar sem linearidade e poder efetuar a diferença enquanto um conjunto de intensidades heterogêneas tal como definidas por Deleuze e Guattari (1995). Não há modelos estruturais e gerativos no devir, porém, agenciamentos de forças múltiplas raras e que se conectam por encontros ao acaso e com uma ausência de sentidos anteriores. Nesse plano, a criança não é uma cópia da família e nem um efeito reduzido desta; assim também a pesquisa não é uma continuidade e cópia de modelos e, muito menos, ramificação de raízes.

Nesse aspecto, devir criança faz da pesquisa em Psicologia experimentação inventiva e deslocamento por diferenciação, multiplicidade e heterogênese de forças singulares e raras. Devir criança permite à Psicologia romper com classificações por semelhança e com a reprodução de modelos das denominadas ciências antigas e legitimadas por controles de variáveis e essencialismos. Ao devir criança, a Psicologia pode se voltar à leitura de Henri Bergson colocando-Ihe problemas verdadeiros a partir das inquietações derivadas da regra régia que confina a intuição a não cientificidade e o tempo duração ao limiar no não exprimível e, portanto, não investigável. Passa-se a lograr "tornar explícito, claro e intuitivo algo que nos habitava pré-reflexivo, opaco e afectivo" (Kastrup, 2004, p. 10).

Dessa forma, a pesquisa ganha vigor e movimento, toma ar e se expande sem dívidas históricas e sem se importar em demasia com os tribunais da verdade e das metodologias. Irá se agenciar clandestinamente com mais força relacional em linhas de composição não lineares. Deleuze 
e Guattari (1992) denominam esse estado de sobrevoo, de permitir-se pensar por sobrevoo, em velocidade intensa com variações distintas. Que a Psicologia se permita fazer sobrevoos.

\section{Duração, um contraponto ao corte da navalha analítica}

A duração é o virtual, "o que só se deixa medir variando de princípio métrico a cada estágio da divisão" (Deleuze, 2006, p. 43). De acordo com Deleuze, a pergunta "o tempo é uno ou múltiplo" não é o que realmente deve importar para aqueles que buscam apreender a realidade no que ela tem de mais profundo. Para ele, "o verdadeiro problema é esse: "qual é a multiplicidade própria ao tempo?" (Deleuze, 1999, p. 63). Eis, portanto, que não se trata mais de conceber a multiplicidade por uma distribuição de imagens extensivas. A duração virtual mergulha numa dimensão temporal, sem imagem, ou melhor, de imagem pura não redutível a coordenadas espaciais. A esse respeito, Zourabichvili parece-nos profícuo:

Que é, pois, o tempo? Ele é a diferença absoluta, a conexão imediata dos heterogêneos, sem conceito idêntico subjacente ou que subsuma. Propriamente falando, o tempo nada é; ele só consiste em diferenças e no revezamento de uma diferença por outra. Ele não tem centro e nem polo identitário (Zourabichvili, 2004, p. 77).

A imagem atual, ou o instante, é já um corte na passagem contínua, é uma interrupção da transformação, é uma espécie de "visão fotográfica" que separa a coisa de seu movimento (Bergson, 1999, pp. 35-36). Já no virtual, o que dura é o devir. Logo, as duas multiplicidades - quantitativa e qualitativa - não são dois mundos isolados. Elas são a contraface uma da outra, duas tendências de um mesmo movimento.

Como observa Deleuze (2006), a partir de Bergson, a ordem espacial da realidade é essencialmente mista. Nós nos deparamos sempre com mistos, "misto do fechado e do aberto, da ordem geométrica e da ordem vital, da percepção e da afecção" (p. 38), pois o virtual envolve o atual. O principal misto examinado por Bergson refere-se à natureza do tempo e sua confusão com o espaço. Dessa, todos os outros mistos derivam e a implicam (Nascimento, 2015).

É por diferenciar-se de si mesmo que o tempo é multiplicidade. Há dois tipos de multiplicidade: a multiplicidade atual, numérica ou quantitativa, e a multiplicidade virtual, qualitativa ou contínua. A primeira multiplicidade, de cunho numérico, diz respeito à variedade material dos entes; ela se define pelo presente dos corpos, por sua existência e distribuição espaço-temporais. Nesse estado de coisas, os seres se definem por sua permanência, por sua constância, e se diferenciam apenas em grau: maior, menor, mais longe, perto, pesado, quente etc. Eles também se transformam, mas o que marca essa transformação são os instantes bem delimitados no tempo e no espaço, de modo que a diferença é apreendida tão-somente pela associação e comparação entre as posições descontínuas.

Na multiplicidade numérica, tudo, portanto, está dado, mesmo que não realizado; as relações se estabelecem entre atuais somente, sejam esses já existentes, sejam ainda da ordem do possível (Deleuze, 1999, pp. 28, 31-32). O outro tipo de multiplicidade, a virtual, não concerne à diferença externa entre os entes, à variedade material dos corpos, mas à própria diferença de natureza de cada um deles. Trata-se não mais de apreender a diferença entre as coisas, porém, a diferença nas próprias coisas.

$\mathrm{E}$, para isso, não basta fazer do interior o reflexo de uma pluralidade quantitativa exterior, quer dizer, não basta dizer que $A$ se compõe ou é divisível em B e C ou então dizer que o movimento temporal é a sucessão de instantes. Em ambos os casos, ainda estaríamos pensando em termos de atualidade numérica e não de uma efetiva diferença de natureza, interna, pura, simples, qualitativa, irredutível ao número.

Passando à multiplicidade virtual, essa não pode ser repartida, pois isso conservaria ainda o princípio de um estado de coisas atual, ainda que abstrato; esta multiplicidade é indivisível: "há outro sem que haja vários, número somente em potência”. Porém, ela não é estática, já que, se assim o fosse, haveria aí uma unidade transcendente e ainda extensiva. Ela é então contínua, continuidade de um puro devir, que "não se divide sem mudar de natureza" (Deleuze, 1999, p. 28). Com efeito, "não se trata de dividir a duração como se dividia o misto: ela é simples, indivisível, pura. Trata-se de uma outra coisa: o simples não se divide, ele se diferencia" (Deleuze, 2006, p. 56). E tal diferenciação, quando levada ao absoluto, devém própria multiplicidade qualitativa. É nesse sentido que Bergson e Deleuze, para referir a essa multiplicidade, falam de tempo duração.

Logo, não faz sentido procurar uma relação numérica entre qualidades que nunca são idênticas e, por isso, não podem ser adicionadas umas às outras. Portanto, um estado interno, o qual só se distingue qualitativamente, nunca é igual a outro, não podendo assim ser sobreposto e comparado; no sentido de buscarmos semelhanças quantitativas, de estabelecermos graus de diferenciação e de construirmos uma multiplicidade numérica, a qual se mostra inteiramente inadequada para representar a realidade interior. Os efeitos dessa argumentação colocam em xeque o uso de escalas e métricas psicológicas

\section{Intuir, um ato de liberdade e rigor no pesquisar}

Se o tempo mensurável está contaminado pelo espaço, então: como operar com o tempo duração correlato da intuição? A saída de tal encruzilhada é encontrada na intuição que logra tratar o tempo em sua duração, sem deter-se exclusivamente em estados dados ou em binarismos baseados na espacialização. A intuição é um método, cujo elemento motor não se reduz à vontade inteligente nem a uma determinação instintiva. 
Para Deleuze, "trata-se de operar uma gênese da intuição, isto é, de determinar a maneira pela qual a própria inteligência se converte e é convertida em intuição" (Deleuze, 1999, p. 89). Compreender a maneira como essa gênese acontece é necessário porque não podemos simplesmente dizer, sem nada explicar, que a intuição é o salto que nos eleva às condições do dado, ou seja, ao monismo do real, pois esse salto abriria margem para diversos tipos de transcendência, de sorte que estaríamos num flerte perigoso com teologismos e suas revelações místicas diversas.

Conforme observa Nascimento (2015), Bergson, em A Evolução criadora (1907/2005), define consciência como contração de instantes. Um instante que interpenetra outro instante, continuamente - haja vista que nossa duração não seria um instante que é substituído por outro instante, porque, caso fossem substitutos, haveria somente presente, contrariando "a duração que é o progresso contínuo do passado que rói o porvir e incha na medida em que avança" (Bergson, 1907/2005, p. 4).

É necessário ir mais longe: essa consciência imediata e essa duração têm um estatuto ontológico singular para além da passagem do tempo em geral. Gilles Deleuze (1966/1999) enfatiza que a intuição foge da concepção de uma espécie de simpatia confusa, não é um pressentimento, não é uma antecipação, ela se faz no campo da complexidade e evita qualquer redução.

Retomando as observações de Deleuze (1999), a intuição é a maneira pela qual alguma coisa se apresenta a uma pessoa imediatamente sem que ela seja definida, inferida ou deduzida. É algo que se apresenta de forma direta, mostrando-se integralmente tal qual ela é. "A intuição é o método do bergsonismo... não é uma simpatia confusa, mas um método elaborado, e mesmo um dos mais elaborados métodos da filosofia" (Deleuze, 1966/1999, p. 7).

O método intuitivo conduz a pesquisa a uma disposição à simpatia com as coisas. Lapoujade (2013) nos ajuda a entender a relação entre intuição e simpatia, indissociavelmente ligadas no pensamento bergsnoniano. Para o autor, a simpatia se torna necessária no pensamento de Bergson, já que a consciência não poderia concluir por si a duração. Deve-se ter em vista, obviamente, que as distinções entre interior e exterior não são fixas, não exibindo uma distinção ontológica. Observe como o autor explica os movimentos complementares da intuição e da simpatia:

Precisemos em que consiste o movimento fundamental da simpatia e da intuição. Cada um deles pode, a partir de então, receber uma definição distinta: a intuição é aquilo pelo qual entramos em contato com o outro em nós (o material, o vital, o social); nesse sentido, ela permanece uma relação de si para si, e não pode ser nada mais do que isso. Inversamente, a simpatia entra em relação com o outro, podemos até mesmo dizer que ela entra no interior desse outro projetando nele nossa interioridade, revelando nele uma direção, uma intenção, uma consciência - que são também os movimentos da nossa própria alteridade interior. Se o espírito pode se tornar matéria - através da intuição -, então a matéria pode se tornar espírito - através da simpatia. (Lapoujade, 2013, p. 66).

Retornando à Evolução Criadora, a maneira pela qual Bergson frequentemente nos apresenta a intuição como um ato simples estabelece uma relação imediata ou direta com a realidade das coisas, isto é, com a duração da consciência ou com o impulso criativo da vida (Nascimento, 2015). A intuição a que alude o autor aborda antes de tudo a duração. Apreende uma sucessão que não é justaposição, porém, um crescimento por dentro, o prolongamento ininterrupto do passado num presente que avança sobre o porvir. É a visão direta do espírito pelo espírito.

A intuição, logo, é uma qualidade da consciência, mas consciência imediata, visão que mal se distingue do objeto visto, conhecimento que é contato e mesmo coincidência. Como o método intuitivo é basilar para o avanço da filosofia da duração, Deleuze arbitra como estratégia de pensamento, que possamos nos desviar das armadilhas colocadas por nossa faculdade intelectiva, a fim de obtermos a simplicidade que nos propõe a intuição (Deleuze, 1966/1999, p. 6).

Segundo as leituras de Deleuze sobre Bergson, a intuição como método pressupõe três regras: uma inicial, que se refere à criação dos problemas, a segunda dedicada à descoberta das verdadeiras diferenças de natureza e a terceira relativa à apreensão do tempo real. A memória bergsoniana é atualização, antes de ser reminiscência. Inversamente, ao inscrever-se na consciência imediata, o passado confere ao humano a profundidade de uma história pessoal que enriquece os seus atos e o sentido de sua liberdade.

A liberdade legítima, na filosofia bergsoniana, começa com um poder de decisão, de inventar os próprios problemas, para que se dissipem os falsos problemas, dando origem à criação dos verdadeiros. "Dessa maneira, a primeira regra consiste em pôr à prova o verdadeiro e o falso aos próprios problemas, denunciar os falsos problemas, reconciliar verdade e criação no nível dos problemas" (Deleuze, 1999, p. 9). Dessa proposição deriva uma questão: como conciliar com um valor de verdade a esse poder de compor problemas?

A segunda regra conduz à decomposição dos mistos segundo suas articulações naturais, isto é, em elementos que diferem por natureza. Ao contrário dos objetos postos no espaço, a realidade da consciência, bem como a duração e a qualidade, não são objetos apreendidos via representação, mas, especialmente, através da experiência no sentido integral. Efetivamente, o tempo-duração não pode ser percebido pela consciência via leis físicas ou sob forma de grandeza, como propõe a psicofísica. As mudanças qualitativas são necessariamente heterogêneas, as quais formam um todo com o dinamismo do qual resulta, como a questão do uno e múltiplo, observados no tópico sobre a multiplicidade qualitativa e quantitativo. A representação no espaço, ao justapor e, portanto, separar o passado do presente, impede toda visão da interpretação qualitativa da consciência. Como as qualidades não possuem forma inteligível, só podemos 
apreender a essência autêntica por apreensão direta, isto é, por um ato de intuição pura.

Deve-se ampliar e ultrapassar a experiência real, a fim de que possamos encontrar as articulações que nos dão essa mesma experiência em todas as suas particularidades. Essa regra visa a mostrar que, tendo um determinado problema sido bem colocado, tende ele por si mesmo a resolver-se. Aqui, o empirismo de Bergson já opera na desarticulação do real em diferenças de natureza, dirigindo-se às condições concretas da experiência real. O que está posto é um princípio de adequação, mais do que verificação ou espelhamento do real.

Podemos agora apresentar a terceira e última regra do método intuitivo concernente à apreensão do tempo real. Para a filosofia bergsoniana, os problemas devem ser resolvidos mais pela perspectiva do tempo-duração do que das coordenadas tempo-espaciais ou como tempo linear. A duração tende a admitir todas as diferenças de natureza; visto que ela pode variar qualitativamente em relação a si mesma, o espaço só assume diferenças de grau, pois ele é multiplicidade quantitativa. Desse modo, para Deleuze (1999), Bergson encontrou uma determinação intrínseca do falso, na expressão "Falso Problema" que nos aponta dois tipos de falsos problemas: problemas inexistentes, que assim se definem, porque seus próprios termos acarretam uma confusão entre o mais e o menos; e problemas mal colocados, que assim se definem por seus termos representarem mistos mal analisados.

\section{Aberturas, pois é cedo para concluir}

Fazer a pesquisa científica em Psicologia ser atravessada pelo devir-criança talvez nos traga algo da leveza que necessitamos para deixar morrer uma forma de conceber o método e deixar que outras emerjam sem um projeto de maioridade da razão seja assumido como princípio norteador. Essa mudança de rumos supõe um rigor que não passa pelo esforço intelectual que paralisa o movimento na tentativa de fixá-lo, mas pela simpatia, intuição, alegria, as quais possibilitam a abertura para a colocação dos verdadeiros problemas ${ }^{1}$, isto é, dos problemas a serviço da vida. Acreditamos que as contribuições bergsonianas sobre intuição como método são importantes para efetuar o que chamamos aqui de devir criança da pesquisa em Psicologia.

Devir-criança que, como prevê o próprio conceito de devir, não se funda na dicotomia entre sujeito e objeto. Com efeito, para o pensador francês, a variedade de obras e estilos na arte funciona como uma reserva de experiências que vão além das descrições e dos ordenamentos convencionais do real reserva que se expande a cada nova obra criada e que instiga, assim, a ampliação de nosso olhar.

1 Bergson aponta dois tipos de falsos problemas: problemas inexistentes, que assim se definem, porque seus próprios termos acarretam uma confusão entre o mais e o menos; e problemas mal colocados, que assim se definem por seus termos representarem mistos mal analisados.
Ciências que levam em conta as proposições de Bergson, certamente, estão próximas do que hoje ainda analisamos como arte ou do que Gilles Deleuze, juntamente com Félix Guattari, definem como devir criança.

Bergson alude a um "estado de hipnose diante da arte". Porém, não apenas na arte. Sem perder de vista a variedade dos casos, artistas, filósofos, cientistas ou qualquer pessoa também podem passar por momentos especiais, contemplando aquilo que está sendo pesquisado, sem o crivo seletivo das necessidades habituais. Ou seja, por via de uma oscilação da atenção, pode-se chegar a ter uma percepção mais complexa ou sutil das coisas, na qual todo ente se mostra constituído pela tensão entre sua atualidade, aparentemente estática, e o fluir temporal que a envolve, num duplo movimento que não cessa de ir de um a outro.

Concordamos com Laurenti (2008), quando vê na estética um caminho por meio do qual "a psicologia poderia ter êxito em conseguir uma formulação adequada a um objeto de estudo processual. Em suma, se ouvirmos as palavras de Bergson, a psicologia científica contemporânea deveria apresentar-se como psicologia estética (Laurenti, 2008, p.52)". Indaga a autora: a Psicologia contemporânea estaria pronta para a revisão dos cânones metodológicos que governam suas formas de expressão resultante do exercício da intuição e da liberdade de pensamento que lhe é correlata?

Reverberações de Bergson são visíveis na Psicologia Contemporânea. Kastrup (1997), por exemplo, ao problematizar os estudos da cognição, introduz a ideia bergsoniana de tempo e abre possibilidades em Psicologia para retomar os estudos da cognição no plano estético e da invenção de problemas. A proposta da autora é abordar o tempo como duração aquele em que coloca em movimento a cognição contemporânea, rechaçando uma ontologia linear e numérica das transformações cognitivas do sujeito. Em outros trabalhos (Kastrup, 2007; 2004), redimensiona o problema da relação entre aprendizagem e atenção em pessoas com ou sem deficiência visual. Se a atenção é condição para aprender ou faz parte do processo de uma aprendizagem inventiva, insere a atenção numa lógica circular, temporal e coletiva. Em diálogo com as obras de Bergson, a autora propõe que consideremos nas pesquisas um tipo de atenção suplementar que não é a da vida prática, mas mergulho na duração.

A intuição como método aproxima a pesquisa da criação e a distância da sistematização como pré-condição para a gênese da produção de conhecimento; avizinha a pesquisa da invenção e a afasta do acabamento; inclina às intensidades e desvia das formas fechadas. Ao recorrermos à intuição, ao invés de recorrermos exclusivamente às operações de dedução ou indução próprias do método científico herdado das ciências modernas, a pesquisa em Psicologia se aproxima da escrita poética, forçando-nos a ultrapassar o uso exclusivo da linguagem referencial quando esse se interpõe à criação, forçando a diferenciações que ao invés de um projeto de ciência se apresenta como plano de experimentação em diferenciação contínua. 


\section{Referências}

Bergson, H. (1999). Matéria e memória: ensaio sobre a relação do corpo com o espírito (Paulo Neves, Trad., 2a. ed.) São Paulo: Martins Fontes. (Trabalho original publicado em 1939).

Bergson, H. (2005). A evolução criadora. (Adolfo Casais Monteiro, Trad.). São Paulo: Martins Fontes.

Bergson, H. (2006). O pensamento e o movente (Prado Neto, B., Trad.). São Paulo: Martins Fontes. (Trabalho original publicado em 1934).

Coelho, J. (1999). Bergson: Intuição e o Método Intuitivo. Trans/Form/ Ação, 21-22(1), 151-164. (Trabalho original publicado em 1998).

Deleuze, G. (1999). Bergsonismo. (L. B. L. Orlandi, Trad.). São Paulo: Ed. 34. (Trabalho original publicado 1966).

Deleuze, G. (2006). A ilha deserta (L. B. L. Orlandi, Trad.). São Paulo: lluminuras. (Trabalho original publicado em 2002).

Deleuze, G. \& Guattari, F. (1992). O que é a filosofia? Rio de Janeiro: Editora 34.

Deleuze, G. \& Guattari, F. (1995). Mil platôs: capitalismo e esquizofrenia (Vol. I). Rio de Janeiro: Editora 34.

Deleuze, G. \& Guattari, F. (1997). Mil platôs: capitalismo e esquizofrenia (Vol. IV). Rio de Janeiro: Editora 34.
Deleuze, G. \& Parnet, C. (1996). Diálogos. Lisboa: Relógio D’Água.

Kastrup, V. (2000). O devir-criança e a cognição contemporânea. Psicologia: Reflexão e Crítica, 13(3), 373-382.

Kastrup, V. (2004). A aprendizagem da atenção na cognição inventiva. Psicologia \& Sociedade, 16 (3): 7-16.

Kastrup, V. (2007). O funcionamento da atenção no trabalho do cartógrafo. Psicologia \& Sociedade, 19(1), 15-22.

Lapoujade, D. (2013). Potências do tempo. São Paulo: n-1 Editora.

Laurenti, C. (2008). Bergsonismo, Psicologia e Liberdade. Psicologia em Estudo, 13(1), 43-52.

Lins, D. (2009). O Devir-Criança do Pensamento. Rio de Janeiro. Forense Universitária.

Nascimento, C. (2015). Reencenação como experimento em artepoliticafilosofia: controvérsias sobre tempo e espaço entre Bergson e Einstein. Dissertação de mestrado em Estudos de Cultura Contemporânea. Universidade Federal de Mato Grosso.

Pelbart, P. (2009). O filho monstruoso. Em Vida Capital: ensaios de Biopolítica. (pp. 174-177). São Paulo, lluminuras.

Zourabichvili, F. (2004). Deleuze: une philosophie de l'événement. Paris: PUF.

\section{Sobre os autores}

Dolores Galindo (dolorescristinagomesgalindo@gmail.com)

Orientadora de Mestrado e Doutorado, Doutorado em Psicologia (Psicologia Social) pela Pontifícia Universidade Católica de São Paulo (2006).

Professora Adjunto I da Universidade Federal de Mato Grosso.

Flávia Cristina Silveira Lemos (flavazevedo@hotmail.com)

Bolsista de Produtividade em Pesquisa 2. Orientadora de Doutorado, Doutorado em História pela Universidade Estadual Paulista Júlio de Mesquita Filho (2007). Professora Associada I da Universidade Federal do Pará.

\section{Caroline Christine Garcia do Nascimento (carollchris@hotmail.com)}

Mestrado em Estudos de Cultura Contemporânea pela Universidade Federal de Mato Grosso (2015). Professora Substituta da Universidade Federal de Mato Grosso.

Leonardo Lemos de Souza (leo.lemos.souza@gmail.com)

Orientador de Mestrado, Orientador de Doutorado. Doutorado em Educação pela Universidade Estadual de Campinas (2008). Professor Assistente Doutor da Universidade Estadual Paulista Júlio de Mesquita Filho.

Roberto Duarte Santana Nascimento (robertodsn@yahoo.com.br),

Doutorado em Filosofia pela Universidade Estadual de Campinas (2012), Professor substituto da Universidade Estadual Paulista - campus de Assis. 
